\title{
Disinformation, Misinformation and Inequality-Driven Mistrust in the Time of COVID-19: Lessons Unlearned from AIDS Denialism
}

\author{
J. Jaiswal ${ }^{1,2,3,5} \cdot$ C. LoSchiavo ${ }^{3} \cdot$ D. C. Perlman ${ }^{4,5}$
}

Published online: 21 May 2020

(C) Springer Science+Business Media, LLC, part of Springer Nature 2020

During a pandemic about which too little is known, public health is facing a crisis on multiple levels, including regarding COVID-19 related- health messaging. With the federal government's inadequate, inconsistent and largely nonevidence-based response [1-3], and the far reach of social media "armchair experts" [4, 5], tremendous uncertainty, fear, and anger has emerged with respect to the origins, treatments and prevention methods regarding COVID-19. Much of the evidence needed to fully inform clinical and public health responses is not yet available, making COVID19 uniquely vulnerable to a proliferation of disinformation, misinformation, and medical mistrust, including what are often called "conspiracy beliefs" [6, 7]. Disinformation (strategically and deliberately spread false information), misinformation (false information, not necessarily with intent to mislead), and mistrust (more than the lack of trust; suspicion of ill intent) are multi-faceted phenomena, with heterogeneous underlying motivating factors. The purpose of this commentary is to suggest that understanding the etiologies of disinformation, misinformation, and medical mistrust must be an important component of the public health response to COVID-19. This is especially critical when considering how the pandemic has affected communities of color, including Asian communities who have been blamed for the

\section{$\triangle$ J. Jaiswal}

jljaiswal@ua.edu

1 Department of Health Science, University of Alabama, Tuscaloosa, AL 35401, USA

2 Center for Interdisciplinary Research on AIDS, Yale University School of Public Health, New Haven, CT 06510, USA

3 Center for Health, Identity, Behavior and Prevention Studies, Rutgers University, Newark, NJ, USA

4 Division of Infectious Diseases, Icahn School of Medicine at Mount Sinai, New York, NY, USA

5 Center for Drug Use and HIV/HCV Research, New York University, New York, NY, USA introduction of SARS-CoV-2 to the U.S. [8, 9] and Black communities who have been blamed for higher fatality rates among Black populations [10]. We propose that two main forms of pushback against dominant scientific evidence have become prominent during COVID-19: (1) disinformation propagated at the institutional/federal government level to preserve power and undermine already marginalized groups, and (2) inequality-driven mistrust among communities that have been made vulnerable by historical and ongoing structural inequities. While these two forms do not constitute a strict dichotomy, this distinction can help inform strategies to address erroneous information and mistrust and inform public health messaging.

"Conspiracy beliefs," characterized as "attempts to explain the ultimate cause of an event...as a secret plot by a covert alliance of powerful individuals or organizations, rather than as an overt activity or natural occurrence" [11], feature prominently in disinformation, misinformation, and inequality-driven mistrust. It can be difficult to persuasively present evidence to refute these types of ideas, especially because experts are often seen as part of the conspiracy [12], and new pieces of contrary evidence can be rationalized into an existing narrative [13]. For example, a Pew Research Center survey conducted in March 2020 found that 29\% of Americans believed that SARS-CoV-2 was developed intentionally in a lab [14], with many pointing to Wuhan, China as the source [15]; President Trump has given this theory institutional legitimacy [16], despite scientific consensus [17-20] and the consensus of the U.S Intelligence services that SARS-CoV-2 is not human-made [21]. This strategic disinformation has served several agendas: casting doubt on evidence presented by Dr. Anthony Fauci, the Director of the National Institute of Allergy and Infectious Diseases and member of the White House Coronavirus Task Force, validating and reinforcing pre-existing xenophobia and racism [22], and redirecting attention away from the White House's inadequate and delayed response to COVID-19. 
State-sanctioned disinformation has proven disastrous in the past. In South Africa during Thabo Mbeki's presidency (1999-2008), AIDS denialism was institutionalized at the highest levels of government. This disinformation delayed official recognition of HIV as the etiology of AIDS and the accessibility of life-saving anti-retroviral therapy, which directly contributed to more than 330,000 preventable deaths [23-26]. These examples of disinformation share some commonalities: assertions and preservations of power, authoritarianism, fear mongering, scapegoating to deflect blame, and the creation or reinforcement of states of collective shock, which can be used to facilitate the implementation of political and economic agendas that are more difficult to achieve during periods of stability [27].

COVID-19 disinformation appears to reflect agendas of white supremacy [28, 29], anxiety over social and economic instability [30], opportunistic unrestrained capitalism, and the cult of personality regarding the president [31, 32]. This is a contrast to the inequality-driven mistrust held by people who continue to experience disenfranchisement [33]. In the COVID-19 pandemic, beliefs about deliberately withheld vaccines $[34,35]$ and the intentional human-made origins of SARS-CoV2 appear to be emerging in some Black communities [36]. While disinformation and inequality-driven mistrust may result in similar or even shared fallacious beliefs, understanding their different origins is vital to delivering effective public health messaging. Government officials promulgating disinformation about the origins of COVID-19 or possible therapies-whether rooted in racism and xenophobia, or whether motivated by goals of deflecting responsibility and accountability-is fundamentally different from marginalized individuals or groups endorsing the same beliefs, for whom mistrust is rooted in ongoing trauma and direct memories of real betrayals [37].

Medical mistrust is well documented among Black people and other populations placed at risk for disproportionate harm [38-45]. For example, endorsement of HIV-related "conspiracy beliefs" is associated with worse HIV-related outcomes among some Black populations [46-48]. This manifestation of HIV-related mistrust can include the beliefs that the U.S. federal government was involved in creating or disseminating HIV as a form of genocide against people of color, that anti-retroviral therapies are harmful, and that a cure is available but is being secretly withheld by the government and pharmaceutical companies $[46,49]$. Referring to these ideas as "conspiracy beliefs" frames these beliefs as being irrational or even paranoid, yet for populations made socially and economically vulnerable by interlocking structures of inequality [50], these ideas are often intergenerational in nature and can resonate strongly with ongoing stigmatizing and exclusionary experiences with healthcare, government, law enforcement, and criminal justice systems
[37, 51-53]. Similarly, inequality-driven mistrust around COVID-19 may deter or prevent individuals from seeking COVID-19-related medical care or adhering to evidencebased COVID-19 prevention guidelines, such as physical distancing and self-quarantining. This is a critical consideration, as Black, Native, and Latinx populations have been disproportionately affected by COVID-19 infection, morbidity, and mortality [54-59, 69], are disproportionately arrested for physical distancing violations [3, 60], and appear to be less likely to receive COVID-19 testing [61]. More effective public health messaging is urgently needed to address these inequities. We suggest the following recommendations:

\section{Bridging the Mistrust Gap}

The onus is on researchers and clinicians to better understand these beliefs and to more effectively bridge the mistrust gaps [62]. A Social Determinants of Health framework [63] can help public health and medical professionals address the impact of population-level inequalities on health outcomes in addition to facilitate enhanced understandings of how social and economic conditions engender inequalitydriven mistrust. It is vital to consider how people, as individuals and as members of groups, experience and interpret social and economic inequality, and how those experiences affect their trust in or mistrust of evidence-based public health messaging, as well as their readiness to accept any promulgated misinformation or disinformation [64].

\section{Addressing Racism}

Public health and medicine must address structural racism directly [65]. Effective public health responses to the pandemic, and to its disproportionate impact on communities of color and other vulnerable populations, must recognize the complex dimensions of mistrust. This requires attention to the issues of structural racism and systematic discrimination which create, perpetuate, and sustain mistrust and influence people's acceptance or rejection of misinformation or disinformation. The failure to fully address differential risk at the community and structural level, and differential risk among various populations placed at greatest risk for harm, further drives mistrust, which then reinforces mistrust arising from people's daily lived experiences of racism, classism, and stigma [66]. Anti-racism education as well as training on research with and care for marginalized populations, must be more fully integrated into public health and medical education [67]. 


\section{Framing the Message}

Avoiding terms like "conspiracy beliefs" may position us to better understand, and thus more effectively address disinformation, misinformation and inequality-driven mistrust that has emerged during this pandemic. Referring to ideas as "conspiracy beliefs" risks obscuring and denying meaningful aspects of people's lived experiences, particularly regarding inequality-driven mistrust, and is an ethical and strategic mistake for public health $[49,68]$. Thus, we propose that public health abandon this term and instead endeavor to identify and distinguish the underpinnings of such beliefs, highlighting how false information may be driven either by agendas of power and racism, or instead driven by mistrust deriving from ongoing social and economic exclusion. This distinction will avoid placing blame on communities that are structurally placed at risk for disproportionate harm by elucidating the role of historical and ongoing social and economic inequalities, while recognizing the forces underlying propagated disinformation and holding accountable those with structural power.

\section{Conclusion}

Distinguishing between disinformation and inequalitydriven mistrust and shifting language away from "conspiracy beliefs" can help avoid pushing people further toward endorsing misinformation and disinformation. Moreover, language without the negative connotations of "conspiracy beliefs" may leave rhetorical space for marginalized populations to express concerns shaped by historical and current trauma, and for public health to better understand why some people endorse such beliefs. Public health and medical professionals have a responsibility to communicate science in an effective, accurate and accessible manner, without bias - and with the understanding that structural racism and other forms of oppression are root causes of inequality-driven mistrust. While erroneous beliefs may appear to similar in nature, the critical distinction is in the source of and paths to those beliefs.

\footnotetext{
Acknowledgements Dr. Jaiswal is supported in part by R25MH087217 and P30 DA011041. Dr. Perlman is supported in part by P30 5P30 DA01104123. Mr. LoSchiavo is supported by the National Center for Advancing Translational Sciences (NCATS), a component of the National Institute of Health (NIH) under award number TL1TR003019. The opinions expressed in this article are the authors' own and do not reflect the view of the authors' institutions, the National Institutes of Health, the Department of Health and Human Services, or the United States government.
}

\section{References}

1. Bursztyn L, Rao A, Roth C, Yanagizawa-Drott D. Misinformation during a pandemic. 2020. https://bfi.uchicago.edu/wp-conte nt/uploads/BFI_WP_202044.pdf. Accessed 4 May.

2. Mitchell A, Oliphant J. Americans immersed in covid-19 news; most think media are doing fairly well covering it. Pew Research Center. https://www.journalism.org/2020/03/18/ameri cans-immersed-in-covid-19-news-mostthink-media-are-doing -fairly-well-covering-it/\#knowledge-misperceptions-and-madeupnews. Accessed 18 Mar 2020.

3. Associated Press. 9 out of 10 people arrested for coronavirus-related offenses in NYC have been Black or Hispanic. Time. https://time.com/5835815/nypd-coronavirus-relatedarr ests/\%0A. Accessed 12 May 2020.

4. Weinman S. The dangerous rise of COVID-19 influencer and armchair epidemiologists. InsideHook. https://www.insidehook .com/article/news-opinion/david-dunning-armchairepidemi ologists-coronavirus. Accessed 21 Apr 2020.

5. Requarth T. Please, let's stop the epidemic of armchair epidemiology. Slate. https://slate.com/technology/2020/03/armch air-epidemiology-coronavirus.html. Accessed March 2020.

6. Vinopal C. Why uncertainty about coronavirus breeds opportunity for misinformation. PBS News Hour. https://www.pbs. $\mathrm{org} /$ newshour/health/why-uncertainty-about-coronavirusbree ds-opportunity-for-misinformation. Accessed 28 Apr 2020.

7. Center for Informed Democracy \& Social Cybersecurity. Coronavirus misinformation and disinformation regarding coronavirus in social media. 2020. https://www.cmu.edu/ideassocia 1-cybersecurity/research/coronavirus.html. Accessed 4 May.

8. Inskeep S. Asian Americans are blamed by some for covid19 outbreak. National Public Radio. https://www.npr. org/2020/03/27/822383360/asian-americans-are-blamed-bysom e-for-covid-19-outbreak. Accessed 27 Mar 2020.

9. Johns Hopkins University Center for Health Security. Blame and discrimination attached to covid-19-an FAQ for us elected leaders and health officials. 2020. https://www.centerforhealth security.org/resources/COVID-19/COVID-19-factsheets/20020 5-nCoV-leadersAgainstStigma.pdf. Accessed 14 May 2020.

10. Kendi IX. Stop blaming Black people for dying of the coronavirus: new data from 29 states confirm the extent of the racial disparities. https://www.theatlantic.com/ideas/archive/2020/04/ race-and-blame/609946/. Accessed 7 May 2020.

11. Douglas KM, Sutton RM. The hidden impact of conspiracy theories: perceived and actual influence of theories surrounding the death of Princess Diana. J Soc Psychol. 2008;148(2):210-22.

12. Sharp D. Advances in conspiracy theory. Lancet. 2008;372(9647):1371-2.

13. Wood MJ, Douglas KM, Sutton RM. Dead and alive: beliefs in contradictory conspiracy theories. Soc Psychol Personal Sci. 2012;3(6):767-73.

14. Schaeffer K. Nearly three-in-ten Americans believe COVID-19 was made in a lab. Pew Research Center. https://www.pewre search.org/fact-tank/2020/04/08/nearly-three-in-tenamericansbelieve-covid-19-was-made-in-a-lab/. Accessed 8 Apr 2020.

15. Peirre J. COVID-19 conspiracy theories: was SARS-CoV-2 made in a lab? Psychology Today. https://www.psychologytoday .com/us/blog/psych-unseen/202004/covid-19conspiracy-theor ies-was-sars-cov-2-made-in-lab. Accessed 21 Apr 2020.

16. Brewster J. A timeline of the COVID-19 Wuhan lab origin theory. Forbes. 2020. https://www.forbes.com/sites/jackbrewst er/2020/05/10/a-timeline-of-the-covid-19-wuhanlab-origi n-theory/\#25420a935aba. Accessed 14 May. 
17. Lu R, Zhao X, Li J, et al. Genomic characterisation and epidemiology of 2019 novel coronavirus: implications for virus origins and receptor binding. Lancet. 2020;395(10224):565-74.

18. Paraskevis D, Kostaki EG, Magiorkinis G, Panayiotakopoulos G, Sourvinos G, Tsiodras S. Full-genome evolutionary analysis of the novel corona virus (2019-nCoV) rejects the hypothesis of emergence as a result of a recent recombination event. Infect Genet Evol. 2020;79:104212.

19. Andersen KG, Rambaut A, Lipkin WI, Holmes EC, Garry RF. The proximal origin of SARS-CoV-2. Nat Med. 2020;26(4):450-2.

20. Calisher C, Carroll D, Colwell R, et al. Statement in support of the scientists, public health professionals, and medical professionals of China combatting COVID-19. Lancet. 2020;395(10226):e42-e4343.

21. Office of the Director of National Intelligence. Intelligence community statement on origins of COVID-19. ODNI News. https:// www.dni.gov/index.php/newsroom/pressreleases/item/2112-intel ligence-community-statement-on-origins-of-covid-19. Accessed 30 Apr 2020.

22. Markel H, Stern AM. The foreignness of germs: the persistent association of immigrants and disease in American society. Milbank Q. 2002;80(4):757-88.

23. Nattrass N. AIDS and the scientific governance of medicine in post-apartheid South Africa. Afr Aff. 2008;107(427):157-76.

24. Zeitz P. Lessons from South Africa's experience of HIV/AIDS. Lancet. 2007;370(9581):19-20.

25. Kalichman SC, Eaton L, Cherry C. "There is no proof that HIV causes AIDS": AIDS denialism beliefs among people living with HIV/AIDS. J Behav Med. 2010;33(6):432-40.

26. Kalichman SC. Denying AIDS: conspiracy theories, pseudoscience, and human tragedy. Berlin: Springer; 2009.

27. Klein N. Screen new deal. The Intercept. https://theinterce pt.com/2020/05/08/andrewcuomo-eric-schmidt-coronavirus-techshock-doctrine/. Accessed 8 May 2020.

28. Perrigo B. White Supremacist groups are recruiting with help from coronavirus-and a popular messaging app. Time. https:// time.com/5817665/coronavirus-conspiracytheories-white-supre macist-groups/. Accessed 8 Apr 2020.

29. Ross J. Coronavirus outbreak revives dangerous race myths and pseudoscience. NBC News. https://www.nbcnews.com/news/ nbcblk/coronavirus-outbreak-revives-dangerousrace-myths-pseud oscience-n1162326. Accessed 19 Mar 2020.

30. Fetzer T, Hensel L, Hermle J, Roth C. Coronavirus perceptions and economic anxiety. 2020. arXiv200303848. https://voxeu.org/ article/coronavirus-perceptions-and-economic-anxiety. Accessed 28 Mar 2020.

31. Jamieson K, Albarracín D. The relation between media consumption and misinformation at the outset of the SARS-CoV-2 pandemic in the US. Harvard Kennedy School Misinformation Review. https://misinforeview.hks.harvard.edu/article/the-relat ionbetween-media-consumption-and-misinformation-at-the-outse t-of-the-sars-cov-2pandemic-in-the-us/. Accessed 14 May.

32. Paz C. All the president's lies about the coronavirus. The Atlantic. https://www.theatlantic.com/politics/archive/2020/04/trumps-liesaboutcoronavirus/608647/. Accessed 9 Apr 2020.

33. Jaiswal J, Halkitis PN. Towards a more inclusive and dynamic understanding of medical mistrust informed by science. Behav Med. 2019;45(2):79-85.

34. Garrison J. Nearly one-third of Americans believe a coronavirus vaccine exists and is being withheld, survey finds. USA Today. https://www.usatoday.com/story/news/politics/2020/04/24/ coronavirus-one-third-usbelieve-vaccine-exists-is-being-withh eld/3004841001/. Accessed 24 Apr 2020.

35. O'Donnell J. "Tuskegee always looms in our minds": some fear black Americans, hardest hit by coronavirus, may not get vaccine. USA Today. https://www.usatoday.com/story/news/healt h/2020/04/19/coronavirus-vaccine-blackamericans-prevention /5146777002/. Accessed 19 Apr 2020.

36. Romano A. Study: nearly a third of Americans believe a conspiracy theory about the origins of the coronavirus. VOX. https://www.vox.com/covid-19-coronavirus-us-responsetr ump/2020/4/12/21217646/pew-study-coronavirus-origins-consp iracy-theory-media. Accessed 12 Apr 2020.

37. Spigner C. Medical apartheid: the dark history of medical experimentation on black Americans from colonial times to the present. J Natl Med Assoc. 2007;99(9):1074.

38. Benkert R, Cuevas A, Thompson HS, Dove-Meadows E, Knuckles D. Ubiquitous yet unclear: a systematic review of medical mistrust. Behav Med. 2019;45(2):86-101.

39. D'Avanzo PA, Bass SB, Brajuha J, et al. Medical mistrust and PrEP perceptions among transgender women: a cluster analysis. Behav Med. 2019;45(2):143-52.

40. Oakley LP, López-Cevallos DF, Harvey SM. The association of cultural and structural factors with perceived medical mistrust among young adult Latinos in rural Oregon. Behav Med. 2019;45(2):118-27.

41. Powell W, Richmond J, Mohottige D, Yen I, Joslyn A, CorbieSmith G. Medical mistrust, racism, and delays in preventive health screening among African-American men. Behav Med. 2019;45(2):102-17.

42. Williamson LD, Smith MA, Bigman CA. Does discrimination breed mistrust? Examining the role of mediated and non-mediated discrimination experiences in medical mistrust. J Health Commun. 2019;24(10):791-9.

43. Guadagnolo BA, Cina K, Helbig P, et al. Medical mistrust and less satisfaction with health care among Native Americans presenting for cancer treatment. J Health Care Poor Underserved. 2009;20(1):210.

44. Gillman J, Davila J, Sansgiry S, et al. The effect of conspiracy beliefs and trust on HIV diagnosis, linkage, and retention in young MSM with HIV. J Health Care Poor Underserved. 2013;24(1):36-45.

45. Quinn KG, Kelly JA, DiFranceisco WJ, et al. The health and sociocultural correlates of AIDS genocidal beliefs and medical mistrust among African American MSM. AIDS Behav. 2018;22(6):1814-25.

46. Bogart LM, Wagner G, Galvan FH, Banks D. Conspiracy beliefs about HIV are related to antiretroviral treatment nonadherence among African American men with HIV. J Acquir Immune Defic Syndr. 2010;53(5):648.

47. Adams LM, Simoni JM. The need for multi-level mitigation of medical mistrust among social network members contributing to antiretroviral treatment nonadherence in African Americans living with HIV: Comment on Bogart. Soc Sci Med. 2016;159:5860.

48. Dale SK, Bogart LM, Wagner GJ, Galvan FH, Klein DJ. Medical mistrust is related to lower longitudinal medication adherence among African-American males with HIV. J Health Psychol. 2016;21(7):1311-21.

49. Jaiswal J, Singer SN, Siegel K, Lekas H-M. HIV-related 'conspiracy beliefs': lived experiences of racism and socio-economic exclusion among people living with HIV in New York City. Cult Health Sex. 2019;21(4):373-86.

50. Crenshaw K. Mapping the margins: Intersectionality, identity politics, and violence against women of color. Stan L Rev. 1990;43:1241.

51. Kutnick AH, Leonard NR, Gwadz MV. "Like i have no choice": a qualitative exploration of HIV diagnosis and medical care experiences while incarcerated and their effects. Behav Med. 2019;45(2):153-65.

52. Goosby BJ, Heidbrink C. The transgenerational consequences of discrimination on African-American health outcomes. Sociol Compass. 2013;7(8):630-43. 
53. Heller J. Rumors and realities: making sense of HIV/AIDS conspiracy narratives and contemporary legends. Am J Public Health. 2015;105(1):e43-e50.

54. Eligon J, Burch A, Searcy D, Oppel Jr R. Black Americans face alarming rates of coronavirus infection in some states. The New York Times. https://www.nytimes.com/2020/04/07/us/coronaviru s-race.html. Accessed 7 Apr 2020.

55. Eligon J, Burch A. Questions of bias in covid-19 treatment add to the mourning for Black families. The New York Times. https:// www.nytimes.com/2020/05/10/us/coronavirusafrican-americansbias.html?auth=login-google\%0A. Accessed 10 May 2020.

56. New York City Department of Health. Age-adjusted rates of lab confirmed COVID19. https://www1.nyc.gov/assets/doh/ downloads/pdf/imm/covid-19-deaths-race-ethnicity04162020-1. pdf\%0A. Accessed 16 Apr 2020.

57. Mineo L. For Native Americans, COVID-19 is "the worst of both worlds at the same time." The Harvard Gazette. https://news.harva rd.edu/gazette/story/2020/05/the-impact-ofcovid-19-on-nativ e-american-communities/. Accessed 8 May 2020.

58. Capatides C. Doctors without borders dispatches team to the Navajo nation. CBS News, May 11 (2020). https://www.cbsne ws.com/news/doctors-without-borders-navajo-nation-coronaviru s/ Accessed 14 May.

59. Jordan M, Oppel AJ. For Latinos and COVID-19, doctors are seeing an 'alarming' disparity. The New York Times, May 11 (2020). https://www.nytimes.com/2020/05/07/us/coronavirus-latin os-disparity.html. Accessed 14 May 2020.

60. Kaplan J, Hardy B. Early data shows Black people are being disproportionally arrested for social distancing violations. ProPublica. https://www.propublica.org/article/in-some-ofohiosmost-populous-areas-black-people-were-at-least-4-times-as-likel y-to-be-chargedwith-stay-at-home-violations-as-whites. Accessed 8 May 2020.

61. Farmer B. The coronavirus doesn't discriminate, but U.S. health care showing familiar biases. National Public Radio. https://www. npr.org/sections/healthshots/2020/04/02/825730141/the-coron avirus-doesnt-discriminate-but-u-s-health-careshowing-famil iar-biases. Accessed 2 Apr 2020.

62. Jaiswal J. Whose responsibility is it to dismantle medical mistrust? Future directions for researchers and health care providers. Behav Med. 2019;45(2):188-96.

63. Marmot M. Social determinants of health inequalities. Lancet. 2005;365(9464):10991104.

64. King J. There's never been a more urgent moment to build Black Americans' trust in the medical System. Mother Jones. https ://www.motherjones.com/politics/2020/05/overcoming-black -communities-distrustmedicine-coronavirus/\%0A. Accessed 8 May 2020.

65. Hardeman RR, Medina EM, Kozhimannil KB. Structural racism and supporting black lives - the role of health professionals. N Engl J Med. 2016;375(22):2113-5.

66. Armstrong K, Putt M, Halbert $\mathrm{CH}$, et al. Prior experiences of racial discrimination and racial differences in health care system distrust. Med Care. 2013;51(2):144.

67. Tsai J, Crawford-Roberts A. A call for critical race theory in medical education. Acad Med. 2017;92(8):1072-3.

68. Mackenzie S. Dissecting the social body: social inequality through AIDS counternarratives. Public Underst Sci. 2011;20(4):491-505.

69. Laster Pirtle WN. Racial capitalism: a fundamental cause of novel coronavirus (COVID-19) pandemic inequities in the United States. Health Edu Behav. 2020. https://doi.org/10.1177/10901 98120922942 .

Publisher's Note Springer Nature remains neutral with regard to jurisdictional claims in published maps and institutional affiliations. 